\title{
Treating Excessive Consumers With Brief Intervention to Reduce Their Alcohol Consumption
}

\section{A Thankless Task?}

\author{
Thomas Fankhänel ${ }^{1,2}$, Benjamin Jovan Panic ${ }^{2}$, Marcus Schwarz², Katrin Schulz ${ }^{2}$, \\ and Thomas Frese ${ }^{1}$ \\ ${ }^{1}$ Institute for General Practice and Family Medicine, Medical Faculty, Martin-Luther-University Halle-Wittenberg, Halle, Germany \\ ${ }^{2}$ Department of Health Psychology, SRH University of Applied Health Science, Gera, Germany
}

\begin{abstract}
Background: General Practitioners' (GP) readiness to implement screening and brief intervention to reduce alcohol consumption of excessive consumers is low. Although several barriers were identified by past research, improving these conditions has not led to improved implementation. Based on Expectancy Value Theory of Achievement Motivation we assume that low seriousness of the health problem in association with the treatment of excessive alcohol consumers may be considered as a crucial barrier too. Aims: By our study, we tested for the influence of the seriousness of the health problem on the GP's readiness to implement brief intervention (BI) in comparison to crucial barriers such as insufficient financial reimbursement and low patient adherence. Method: In order to manipulate the seriousness of the health problem GPs were confronted with three different situations each introducing a fictitious patient with either excessive alcohol consumption, or binge drinking, or harmful alcohol consumption. Results: Questionnaires of 185 GPs were analyzed. As hypothesized GPs were less ready to treat patients with excessive consumption in comparison to patients with harmful consumption, $t(184)=5.51, p<.001, d=.40$, and binge drinking, $t(184)=6.14, p<.001, d=.43$. Their readiness was higher in case of high adherence, $F(1,181)=17.35, p<.001, \eta^{2}=.09$. Limitations: Recruitment of GPs was based on voluntary participation. GPs had to assess their readiness in the artificial context of case vignettes. Conclusion: GPs' readiness to implement a BI was influenced by the seriousness of the health problem and expected patient adherence. No such effect was found for financial reimbursement.
\end{abstract}

Keywords: general practice, brief intervention, excessive alcohol consumption, implementation readiness, financial reimbursement

In Germany, $18 \%$ of men and $14 \%$ of women were excessive alcohol consumers (Drogen- und Suchtbericht der Bundesregierung, 2019). Excessive alcohol consumption is defined either by a daily limit of pure alcohol consumption (24 $\mathrm{g}$ for men and $12 \mathrm{~g}$ for women (Gunzerath et al., 2004) or by questionnaire score (e.g., AUDIT-C; Bush et al., 1998) and should be distinguished from other forms of unhealthy alcohol consumption such as harmful consumption and binge drinking (AWMF et al., 2016). Harmful consumption is defined as alcohol consumption that has led either to physical damage (e.g., liver cirrhosis) or mental damage (e.g., episodes of depressive disorder secondary to heavy consumption) (World Health Organization [WHO], 2004). The National Institute on Alcohol Abuse and Alcoholism defines binge drinking as a pattern of consumption that causes blood alcohol concentration to rise to $.08 \%$ or more that typically occurs after a woman consumes four drinks or a man consumes five standard drinks in about $2 \mathrm{hr}$ (White et al., 2018). A standard drink contains $14 \mathrm{~g}$ of pure alcohol (e.g., 0.331 of beer). In the Global Status Report on Alcohol and Health (WHO, 2018) binge drinking (or heavy episodic drinking) is defined as a pattern of consumption in which 60 or more grams of pure alcohol are consumed on at least one occasion at least once a month. The general practice setting can be considered an ideal locus for early detection of excessive alcohol consumption due to its high contact exposure to the population. Preventive approaches such as screening and brief intervention (SBI) have been shown to be effective in reducing alcohol consumption in general practice patients (Grothues et al., 2008; Kaner et al., 2018) and have been hence widely recommended (AWMF et al., 2016; WHO, 2017). Brief interventions (BIs) may include information about the adverse effects of alcohol, on how the patients' alcohol consumption compares with recommended limits, or on the benefits of drinking less (Aalto et al., 2001). BIs should be implemented in an empathetic, respectful, positive relationship with the patient. GPs should work with the person's own ideas, concerns and 
motivations by using active listening skills, including openended questions, and affirmations in order to encourage the patients to take personal responsibility for their decisions (Babor et al., 2001). Despite its proven effect, most GPs have not implemented BI into their routine practice (Aalto et al., 2002; Anderson, 2009; Anderson, Bendtsen, et al., 2016; Beich et al., 2002; Edlund et al., 2004; Heather, 2012; Nygaard \& Aasland, 2011). To understand this phenomenon, some studies have been conducted in the last two decades (Fankhänel, Lenz, et al., 2014; Johnson et al., 2011; Nilsen, 2010; Rapley et al., 2006; Wilson et al., 2011) revealing a large number of barriers including organizational factors (e.g., lack of financial incentives), staff factors (e.g., lack of knowledge), patient factors (e.g., negative reaction in terms of embarrassment or unease) (Johnson et al., 2011; Nygaard et al., 2010), individual-level factors (lack of education), or society-level factors (heterogeneous understanding of the alcohol problem) (Nilsen, 2010). These findings can be interpreted in at least two different ways. They can be interpreted firstly as the disclosure of $\mathrm{BI}$ as a badly designed and possibly too demanding treatment not feasible for the target group of excessive consumers in primary care. It can also be interpreted as indicative of the GPs' uncertainty regarding what really prevents them from implementing a well-approved intervention.

To advance the discourse we want to approach the problem by referring to the Expectancy Value Theory of Achievement Motivation (Bierbauer et al., 2017; Friedman et al., 2007; Prentice-Dunn et al., 2009; Schwarzer et al., 2011; Wigfield \& Eccles, 2000). According to the theory, two factors primarily determine the motivation or readiness to show a certain behavior. First, readiness depends upon the probability to attain an intended outcome by the behavior which can be termed effectiveness. The readiness will be low when the probability is low (Wigfield \& Eccles, 2000). The GPs' low readiness to implement BI may be thus a consequence of their belief that BI is not effective in reducing the alcohol consumption of excessive consumers. The GPs' belief may be the consequence, for instance, of some patients' lack of adherence. GPs may use the patients' outwardly shown adherence as an indicator for the intervention effectiveness since the attainment of the intervention goal, that is, a reduction of alcohol consumption can hardly be monitored by the GPs. Lack of adherence and the belief of being ineffective were accordingly identified by previous research as main sources of frustration and low motivation when working with alcohol issues (Beich et al., 2002; Fankhänel, Klement, et al., 2014; Wilson et al., 2011; Mules et al., 2012).

Second, the Expectancy Value Theory of Achievement Motivation assumes, moreover, that the readiness for a certain behavior depends also on the value that a potential actor ascribes to the outcome or intended goal (Wigfield \& Eccles, 2000). Low BI readiness could be explained thus additionally by a low value that the GPs may ascribe to the potential outcome of their BI (Beich et al., 2002). What could cause such an ascription? This question cannot be answered easily. Two options may be considered. GPs may perceive the BIs' target group of excessive consumers as not endangered enough in order to receive treatment. Excessive consumption should be identified, for instance, by means of screening questionnaires such as AUDIT-C (Bush et al., 1998) which primarily focuses on a patients' consumption level (Bradley et al., 2007) (Dawson et al., 2005). In contrast to other forms of unhealthy alcohol consumption such as harmful consumption or binge drinking, both implicating some larger risk of organic harm or mortal danger, the treatment of excessive consumers may be perceived as less valuable by the GPs suggesting the belief of a low outcome value for the patient that was treated by BI. Such a low outcome value could however also be caused by the belief of being insufficiently reimbursed suggesting a low outcome value for the GP. Accordingly, GPs have identified lack of financial reimbursement as an important barrier (Anderson et al., 2017; Anderson, Wojnar, et al., 2016; Fankhänel, Klement, et al., 2014; Keurhorst et al., 2013; Khadjesari et al., 2017; Nilsen, 2010). In the ODHIN trial, an experimentally introduced reimbursement delivered during a 12-week implementation period (fee for service) increased the proportion of excessive consumers given an intervention (Anderson, Bendtsen, et al., 2016). However, no lasting effect was found at the 9 months follow-up after the additional reimbursement had been cancelled (Anderson et al., 2017). In Germany GPs are paid per performance based on a payment standard valid throughout Germany (Einheitlicher Bewertungsmaßstab [EBM]; Kassenärztliche Bundesvereinigung, 2015) and were scheduled by approximately $10 €$ for $10 \mathrm{~min}$ of interventional talk, for instance, to treat patients with excessive alcohol consumption.

To summarize, based on Expectancy Value Theory of Achievement Motivation three possible barriers can be identified: first: lack of effectiveness because of non-adherent patients, second: low outcome value for the patient because of believing that excessive consumption is not a justified cause for treatment and, third: low outcome value for the GP because of insufficient financial reimbursement.

To investigate the relative effect of these three factors we conducted a vignette study to test the following three corresponding hypotheses:

Hypothesis 1 (H1): GPs are more ready to implement $\mathrm{BI}$ in case of harmful alcohol consumption and binge drinking and are less ready in the case of excessive consumption. 
Hypothesis 2 (H2): GPs are more ready to implement BI for patients with high adherence and are less ready in the case of patients with low adherence.

Hypothesis 3 (H3): Higher financial reimbursement may have the potential to improve the GPs' readiness to implement BI.

\section{Methods}

\section{Design and Setting}

We planned a cross-sectional, randomized vignette study using a 3 (excessive consumption/harmful consumption/ binge drinking) $\times 2$ (adherence high/low) $\times 2$ (standard reimbursement $18 €$ /above standard reimbursement 36 $€)$ design. For randomization of GPs, we used a PC random generator determining the order of questionnaires. A convenience sample of GP offices was recruited by conducting a spontaneous visit by a research assistant during opening hours. In an attempt to attain our recruitment goal of 200 participants, 246 GPs practicing in the German federal states Hesse, Saxony, Saxony-Anhalt, and Thuringia were consulted personally at their general practice offices by nine research assistants. On-site, the practice nurse was informed about the study and asked about inviting their GP to participate. At the time of GPs' consent to participate, study information, consent forms, questionnaire, and the payment-sheet were handed over to them. The completed study materials were gathered in a follow-up practice visit. Each GP completing the questionnaire received a financial reimbursement of $25 €$.

\section{Materials}

\section{Questionnaire}

The questionnaire was developed by an interdisciplinary team of GPs, social scientists, and psychologists experienced in their respective fields of research. It was selfdesigned and development followed the concept of face validity. The questionnaire was pretested by scientifically experienced GPs and the feedback led to minor modifications. Piloting was done with a subsample of eight GPs. It included an introduction, demographic questions, as well as three case vignettes to assess the GPs' implementation readiness under different conditions.

GPs were first informed about the recommendation (AWMF et al., 2016; WHO, 2017) that each primary care patient should be screened systematically for alcohol consumption and treated by BI in case of excessive alcohol consumption. They were then instructed about the investigation, followed by three case vignettes each depicting a fictitious patient with one of three patterns of unhealthy alcohol consumption: risky consumption, harmful consumption, or binge drinking (see Appendix). Each GP received the three vignettes. To avoid order effects the vignettes were presented in random order to the sample. Each vignette provided furthermore the patient adherence and the financial reimbursement manipulation.

Patient adherence manipulation: Half of the GPs were informed that the fictitious patient responds affirmatively to the information that his excessive alcohol consumption should be treated (high adherence condition) whereas the other half was informed that the fictitious patient responds negatively to this information (low adherence condition).

Financial reimbursement manipulation: Half of GPs were additionally informed that they would receive a financial reimbursement of $18 €$ (18-€ condition) for implementing a 10-minute $\mathrm{BI}$ whereas the other half were informed that they would receive $36 €$ (36-€ condition) for implementing a 10-minute BI.

The vignettes were presented in random order. After reading the vignettes GPs were asked to assess their implementation readiness in relation to the three depicted patients by using a 6-item Likert scale with the items ranging from 1 (= do not at all agree) to 6 (=do fully agree). Items are shown in Table 1.

Finally, demographic data and practice information of GPs were gathered. SPSS statistical software (version 22.0) was used to calculate means as well as standard deviations and to run $\mathrm{AN}(\mathrm{C}) \mathrm{OVAs}$ for continuous variables. A statistically significant difference was stated for $p<.05$. The a priori power analyses to determine an adequate sample size yielded at least 188 participants to provide a statistical power of $95 \%$ or more at a $5 \% \alpha$-level. Due to the lack of published research in the given field, the effect sizes of the estimated effect in the population was therefore set to a medium effect according to the conventional standards on effect sizes introduced by Cohen (1988).

\section{Results}

Single missing values led to case-wise exclusion from the further analysis, while eight statistical outliers were identified and excluded. Since sphericity was violated the Greenhouse-Geisser correction has been applied for the mixed ANOVA procedure. Finally, questionnaires of 185 GPs were analyzed (response rate 68\%). The mean age of GPs was 51 years $(S D=9.54)$ with a mean of 15 years in practice $(S D=9.40)$. More than half of the GPs were women (64.6\%), 132 managed an urban practice (71.4\%), and 76 worked in a group practice, in a practice sharing, or were employed in an ambulatory health care center (41.1\%). Implementation readiness was assessed by a 6-item Likert-scale with good reliability (Cronbach's $\alpha=.91$ ). 
Table 1. Mean implementation readiness of GPs as a function of scale items

\begin{tabular}{|c|c|}
\hline Bl activity & Mean $\mathrm{Bl}$ readiness $(S D)$ \\
\hline I would try to inform the patient about the negative consequences of alcohol consumption. & $4.92(1.07)$ \\
\hline I would try to motivate the patient to reduce his or her alcohol consumption. & $4.61(1.21)$ \\
\hline I would try to arrange behavioral strategies to help the patient reducing his or her alcohol consumption. & $5.03(1.01)$ \\
\hline I would try to summon the patient a second time in order to control for his or her consumption reduction. & $4.15(1.27)$ \\
\hline I would try to argue about the patients' arguments against a reduction of his or her alcohol consumption. & $4.16(1.33)$ \\
\hline I would try to help the patient find solutions for his or her personal problems. & $4.40(1.42)$ \\
\hline
\end{tabular}

GPs reported a mean readiness of $4.55(S D=0.93)$. In the low adherence condition 67 participants were female and 33 male (33.0\%); in the high adherence condition 50 were female and 31 male (38.3\%). In the $18-€$ condition 55 participants were female and 29 male (34.5\%), in the $36-€$ condition 62 were female and 35 male (36.1\%). GPs of the low adherence condition $(M=52.7, S D=9.63)$ were older than the GPs of the high adherence condition $(M=48.5, S D=$ $8.94), t(169)=2.97, p<.01$. No difference of age was found between GPs of the $18-€$ condition $(M=51.7, S D=9.82)$ and the 36-€ condition $(M=50.1, S D=9.28), t(177)=$ $1.04, p=.300$.

A mixed-effects model with unhealthy alcohol consumption (excessive consumption/harmful consumption/ binge drinking) as a within-subjects factor, adherence (high/ low) and reimbursement $(18-€ / 36-€)$ as between-subjects factors, and implementation readiness as dependent variable revealed a main effect for unhealthy alcohol consumption, $F(1.78,322.76)=24.80, p<.001, \eta^{2}=.12$. We found lower readiness for excessive consumption $(M=4.22$, $S D=1.19)$ in comparison to harmful consumption $(M=$ $4.70, S D=1.14), t(184)=5.51, p<.001, d=.40$, and binge drinking $(M=4.72, S D=1.01), t(184)=6.14, p<.001, d=$ .43. A second main effect was found for adherence, $F(1,181)=17.35, p<.001, \eta^{2}=.09$. GPs indicated higher readiness when the patient responded adherently $(M=$ $4.91, S D=0.76)$ in comparison to low adherence $(M=$ $4.23, S D=1.04)$. No such main effect could be found for financial reimbursement, $F(1,181)=0.34, p=.561, \eta^{2}=.00$.

\section{Discussion}

By means of case vignettes, we tested for the effect of three barriers against the implementation of BI: lack of adherence, low outcome value for the patient in case of excessive consumption, and/or low outcome value for the GP because of unsatisfactory financial reimbursement. As expected, GPs showed lower readiness when patients were excessive consumers in comparison to harmful consumers or binge drinkers. Both comparisons revealed small to medium effect sizes (Cohen, 1988). Also, they showed higher readiness when the patient responded adherently.
To summarize, according to Expectancy Value Theory of Achievement Motivation our results show that the GPs' readiness to implement $\mathrm{BI}$ seems to depend primarily on the patients' adherence and the perceived seriousness of the health problem (outcome value for the patient). GPs are more ready to implement BI when a patient indicates high adherence possibly because of being associated with the expectation that the intended outcome of reduced alcohol consumption will be really attained. Furthermore, GPs may expect increased workload in relation to patients with low adherence. The term of adherence implicates - in addition to the term of compliance - the patients' discernment that following the GPs' instructions will have beneficial consequences (Glasgow \& Anderson, 1999). Hence, GPs may associate low adherence with low readiness to change (DiClemente et al., 1991) and the need to motivate such patients more laboriously for a reduction of their alcohol consumption. Increased financial reimbursement may have the potential to neutralize this negative effect of increased workload (Anderson et al., 2017).

GPs may be more ready too when patients indicate a more serious health problem such as harmful consumption or binge drinking. These behaviors may be associated with some higher implementation outcome value for the patient. In contrast, excessive consumption may be less associated with crucial aspects such as organ damage, psychiatric disorder, or risk of dying, making BI seem less urgent. Moreover, excessive consumption is defined either by a daily limit of pure alcohol consumption (24 g for men and $12 \mathrm{~g}$ for women; Gunzerath et al., 2004) or by questionnaire score (e.g., AUDIT-C; Bush et al., 1998). According to previous research in Germany, $18 \%$ of men and 14\% of women drank more than the recommended level and belong thus to the large population of excessive consumers (Drogen- und Suchtbericht der Bundesregierung, 2019). When following the recommendation for systematic screening of any patient GPs would have to provide the capacity to treat nearly every seventh patient visiting their general practice. Considering the limited resources of GPs, this procedure may lead at least to undesirable consequences such as increased workload or reduced ability to provide other medical treatments due to time constraints.

To advance the discourse we want to suggest a new perspective. We believe that talking in terms of barriers 
implicates that an aspired activity - implementing a brief intervention for patients screened positive - is not translated into action because of one or more barriers preventing an actor - the GP - from the action. If this is true, the elimination of barriers such as insufficient reimbursement should result in action and widespread implementation of BI. Since such a widespread implementation has not been attained a new perspective may be considered. Recent empirical research results seem to support this idea (Coleman, 2010; Town et al., 2005) showing that, for instance, financial incentives increased the propensity to record health promotion counseling activities but not their implementation (Coleman, 2010). Although regarded as the dominant barrier by some researchers (Anderson et al., 2017) improved financial reimbursement (fee for service) did not lead to a lasting effect. Hence, in contrast to the barriers-account, we suppose that some inherent characteristics of BI may be relevant too. For instance, when using BI, GPs are forced to convince excessive drinkers to reduce their alcohol consumption by means of advice and gentle forms of persuasive communication (e.g., Motivational Interviewing; Burke et al., 2003) possibly resulting in a tough debate with difficulty to refute disagreement, hostile response and feigned compliance (Rapley et al., 2006). We presume hence that future research should investigate especially these inherent characteristics more thoroughly.

\section{Limitations}

There are some limitations to the present study. First, the recruitment of GPs based on voluntary participation should be noted implicating selection bias and the risk of results with limited representativeness. Voluntary participation was implemented by the Ethics Committee of the University of Halle and is a widespread practice in this field of research. Second, the self-reported intention to implement a certain BI associated activity was used as a predictor of the GPs' readiness possibly limiting the generalizability of our results. Self-reports, especially regarding desired or recommended behaviors such as BI, are possibly biased toward social desirability and would hence indicate a higher readiness than will be shown in routine care. However, using intention as a predictor of future behavior is an accepted practice in psychological research. Its predictive validity can be increased by using items specific to the context in question. This condition was met in our study. Third, GPs had to assess their readiness based on verbal information in the artificial context of case vignettes. Verbal information may provide a reduced and abstracted picture of the real conditions possibly inducing a weaker effect than realworld conditions would do. Case vignettes are perceived however as a valid strategy to measure clinical competence providing results that be transferred to real contexts
(Kathiresan \& Patro, 2013; Peabody et al., 2000, 2004; Schröder et al., 2015; Sowden et al., 2017). Fourth, excessive consumers should be determined by systematic screening by means of screening questionnaires. The screening is understood as a preparatory step of BI. Although with regard to general practice, the feasibility of this approach may be questioned, the associated problem of identifying the right patients was not addressed by our research. We believe that the complexity of this problem suggests further investigation, also taking into account organizational and psychological aspects.

\section{Conclusions}

Past research has emphasized that several barriers may prevent GPs from implementing BI into routine care. We assume that the remarkable number of barriers may rather indicate a more complex problem that cannot be solved by only improving reimbursement. Accordingly, empirically improved reimbursement has not led to the expected increase of implementation (Anderson et al., 2017). We show that the GPs' implementation readiness can be influenced more intensively by the barriers low outcome value for the patient in case of excessive consumers and perceived low patient adherence. These two characteristics should be investigated more thoroughly by future research in order to initiate a modification process of the (S)BI approach. To our knowledge, only a modification of the (S)BI approach may have the potential to improve the GPs' implementation readiness. Such an improvement would be very desirable especially because of the immense health damage caused by excessive alcohol consumption.

\section{References}

Aalto, M., Pekuri, P., \& Seppa, K. (2001). Primary health care nurses' and physicians' attitudes, knowledge and beliefs regarding brief intervention for heavy drinkers. Addiction, 96(2), 305-311. https://doi.org/10.1046/j.1360-0443.2001.96230514.x

Aalto, M., Pekuri, P., \& Seppa, K. (2002). Primary health care professionals' activity in intervening in patients' alcohol drinking: A patient perspective. Drug and Alcohol Dependence, 66(1), 39-43. https://doi.org/S037687160100179X

Anderson, P. (2009). Overview of interventions to enhance primary-care provider management of patients with substanceuse disorders. Drug and Alcohol Review, 28(5), 567-574. https://doi.org/10.1111/j.1465-3362.2009.00113.x

Anderson, P., Bendtsen, P., Spak, F., Reynolds, J., Drummond, C., Segura, L., Keurhorst, M., Palacio-Vieira, J., Wojnar, M., Parkinson, K., Colom, J., Kloda, A., DeLuca, P., Baena, B., Newbury-Birch, D., Wallace, P., Heinen, M., Wolstenholme, A., van Steenkiste, B., ... Gual, A. (2016). Improving the delivery of brief interventions for heavy drinking in primary health care: outcome results of the Optimizing Delivery of Health Care 
Intervention (ODHIN) five-country cluster randomized factorial trial. Addiction, 111(11), 1935-1945. https://doi.org/10.1111/ add.13476

Anderson, P., Coulton, S., Kaner, E. F., Bendtsen, P., Kloda, K., Reynolds, J., Segura, L., Wojnar, M., Mierzecki, A., Deluca, P., Newbury-Birch, D., Parkinson, K., Okulicz-Kozaryn, K., Drummond, C., \& Gual, A. (2017). Delivery of brief interventions for heavy drinking in primary care: Outcomes of the ODHIN 5 country cluster randomized trial. Annals of Family Medicine, 15 (4), 335-340. https://doi.org/10.1370/afm.2051

Anderson, P., Wojnar, M., Jakubczyk, A., Gual, A., Segura, L., Sovinova, H., Csemy, L., Kaner, E., Newbury-Birch, D., Fornasin, A., Struzzo, P., Ronda, G., van Steenkiste, B., Keurhorst, M., Laurant, M., Ribeiro, C., do Rosario, F., Alves, I., Scafato, E., ... Kolsek, M. (2016). Managing alcohol problems in general practice in Europe: Results from the European ODHIN Survey of General Practitioners. Alcohol and Alcoholism, 51(5), 630. https://doi.org/10.1093/alcalc/agw055

AWMF.DGPPN \& DG-Sucht. (2016). S3-guideline "Screening, diagnosis and treatment of alcohol-related disorders". Association of the Scientific Medical Societies, German Society for Psychiatry and Psychotherapy, Psychosomatic, and Neurology, \& German Society for Addiction Research and Addiction Therapy e.V.

Babor, T. F., Higgins-Biddle, J., Saunders, J., \& Monteiro, M. (2001). AUDIT: The Alcohol Use Disorders Identification Test: Guidelines for use in primary care (2nd ed.). World Health Organization.

Beich, A., Gannik, D., \& Malterud, K. (2002). Screening and brief intervention for excessive alcohol use: Qualitative interview study of the experiences of general practitioners. British Medical Journal, 325(7369), 870.

Bierbauer, W., Inauen, J., Schaefer, S., Kleemeyer, M. M., Luescher, J., König, C., Tobias, R., Kliegel, M., Ihle, A., Zimmerli, L., Holzer, B. M., Siebenhuener, K., Battegay, E., Schmied, C., \& Scholz, U. (2017). Health behavior change in older adults: Testing the health action process approach at the inter-and intraindividual level. Applied Psychology: Health and Well-Being, 9(3), 324-348. https://doi.org/10.1111/aphw.12094

Bradley, K. A., DeBenedetti, A. F., Volk, R. J., Williams, E. C., Frank, D., \& Kivlahan, D. R. (2007). AUDIT-C as a brief screen for alcohol misuse in primary care. Alcoholism: Clinical and Experimental Research, 31(7), 1208-1217. https://doi.org/ 10.1111/j.1530-0277.2007.00403.x

Burke, B. L., Arkowitz, H., \& Menchola, M. (2003). The efficacy of motivational interviewing: A meta-analysis of controlled clinical trials. Journal of Consulting and Clinical Psychology, 71(5), 843861. https://doi.org/10.1037/0022-006X.71.5.8432003-07816-001

Bush, K., Kivlahan, D. R., McDonell, M. B., Finn, S. D., \& Bradley, K. A. (1998). AUDIT Alcohol Consumption Questions (AUDIT-C): An effective brief screening test for problem drinking. Ambulatory Care Quality Improvement Project (ACQUIP). Alcohol Use Disorders Identification Test. Archives of Internal Medicine, 158 (16), 1789-1795.

Cohen, J. (1988). Statistical power analysis for the behavioral sciences (2nd ed.). Academic Press.

Coleman, T. (2010). Do financial incentives for delivering health promotion counselling work? Analysis of smoking cessation activities stimulated by the quality and outcomes framework. BMC Public Health, 10, Article 167. https://doi.org/10.1186/ 1471-2458-10-167 1471-2458-10-167

Dawson, D. A., Grant, B. F., Stinson, F. S., \& Zhou, Y. (2005). Effectiveness of the derived Alcohol Use Disorders Identification Test (AUDIT-C) in screening for alcohol use disorders and risk drinking in the US general population. Alcoholism: Clinical and Experimental Research, 29(5), 844-854. https://doi.org/ 00000374-200505000-00019

DiClemente, C. C., Prochaska, J. O., Fairhurst, S. K., Velicer, W. F., Velasquez, M. M., \& Rossi, J. S. (1991). The process of smoking cessation: An analysis of precontemplation, contemplation, and preparation stages of change. Journal of Consulting and Clinical Psychology, 59(2), 295-304. https://doi.org/10.1037/ 0022-006x.59.2.295

Drogenbeaufragte der Bundesregierung. (Eds.). (2019). Drogen- und Suchtbericht 2019 [Report on drugs and addiction]. Federal Ministry for Health. https://www.bundesgesundheitsministerium. de/fileadmin/Dateien/5_Publikationen/Drogen_und_Sucht/ Berichte/Broschuere/Drogen-_und_Suchtbericht_2019_barr.pdf

Edlund, M. J., Unutzer, J., \& Wells, K. B. (2004). Clinician screening and treatment of alcohol, drug, and mental problems in primary care: Results from healthcare for communities. Medical Care, 42(12), 1158-1166. https://doi.org/00005650200412000-00002

Fankhänel, T., Klement, A., \& Forschner, L. (2014). Hausärztliche Intervention für eine Langzeitentwöhnungsbehandlung für Patienten mit Suchterkrankung (HELPS) [General practitioner intervention for a long-term weaning treatment in patients with dependency (HELPS)]. Sucht Aktuell, 21(2), 55-59.

Fankhänel, T., Lenz, J., Papert, S., Voigt, K., \& Klement, A. (2014). Screening und Brief Intervention in der Hausarztpraxis: Barrieren gegen eine Frühintervention bei Patienten mit Alkoholmissbrauch [Screening and brief intervention in general practice: Barriers against early intervention in patients with alcohol misuse]. Psychotherapie/Psychosomatik/Medizinische Psychologie, 64(9/10), 373-377.

Friedman, B. A., Cox, P. L., \& Maher, L. E. (2007). An Expectancy Theory Motivation Approach to Peer Assessment. Journal of Management Education, 32(5), 580-612. https://doi.org/ $10.1177 / 1052562907310641$

Glasgow, R. E., \& Anderson, R. M. (1999). In diabetes care, moving from compliance to adherence is not enough. Something entirely different is needed. Diabetes Care, 22(12), 20902092. https://doi.org/10.2337/diacare.22.12.2090

Grothues, J. M., Bischof, G., Reinhardt, S., Meyer, C., John, U., \& Rumpf, H. J. (2008). Effectiveness of brief alcohol interventions for general practice patients with problematic drinking behavior and comorbid anxiety or depressive disorders. Drug and Alcohol Dependence, 94(1-3), 214-220. https://doi.org/ 10.1016/j.drugalcdep.2007.11.015

Gunzerath, L., Faden, V., Zakhari, S., \& Warren, K. (2004). National Institute on Alcohol Abuse and Alcoholism report on moderate drinking. Alcoholism: Clinical and Experimental Research, 28(6), 829-847. https://doi.org/00000374-200406000-00002

Heather, N. (2012). Can screening and brief intervention lead to population-level reductions in alcohol-related harm? Addiction Science \& Clinical Practice, 7(1), Article 15. https://doi.org/ 10.1186/1940-0640-7-15 1940-0640-7-15

Johnson, M., Jackson, R., Guillaume, L., Meier, P., \& Goyder, E. (2011). Barriers and facilitators to implementing screening and brief intervention for alcohol misuse: A systematic review of qualitative evidence. Journal of Public Health, 33(3), 412-421. https://doi.org/10.1093/pubmed/fdq095

Kaner, E. F. S., Beyer, F. R., Muirhead, C., Campbell, F., Pienaar, E. D., Bertholet, N., Daeppen, J. B., Saunders, J. B., \& Burnand, B. (2018). Effectiveness of brief alcohol interventions in primary care populations. Cochrane Database of Systematic Reviews, (2), CD004148. https://doi.org/10.1002/14651858.CD004148.pub4

Kassenärztliche Bundesvereinigung. (2015). Einheitlicher Bewertungsmaßstab (EBM) [Uniform Assessment Standard (EBM)]. https://www.kbv.de/html/online-ebm.php 
Kathiresan, J., \& Patro, B. K. (2013). Case vignette: A promising complement to clinical case presentations in teaching. Education for Health (Abingdon), 26(1), 21-24. https://doi.org/ 10.4103/1357-6283.112796

Keurhorst, M. N., Anderson, P., Spak, F., Bendtsen, P., Segura, L., Colom, J., Reynolds, J., Drummond, C., Deluca, P., van Steenkiste, B., Mierzecki, A., Kõõloda, K., Wallace, P., NewburyBirch, D., Kaner, E., Gual, T., \& Laurant, M. G. (2013). Implementing training and support, financial reimbursement, and referral to an internet-based brief advice program to improve the early identification of hazardous and harmful alcohol consumption in primary care (ODHIN): Study protocol for a cluster randomized factorial trial. Implementation Science, 8, Article 11. https://doi.org/10.1186/1748-5908-8-11 1748-5908-8-11

Khadjesari, Z., Hardoon, S. L., Petersen, I., Hamilton, F. L., \& Nazareth, I. (2017). Impact of financial Incentives on alcohol consumption recording in primary health care among adults with schizophrenia and other psychoses: A cross-sectional and retrospective cohort study. Alcohol and Alcoholism, 52(2), 197205. https://doi.org/10.1093/alcalc/agw076

Mules, T., Taylor, J., Price, R., Walker, L., Singh, B., Newsam, P., Palaniyappan, T., Snook, T., Ruselan, M., Ryan, J., Santhirasegaran, J., Shearman, P., Watson, P., Zino, R., Signal, L., \& Fouge, G. (2012). Adressing patient alcohol use: A view from general practice. Journal of Primary Health Care, 4(3), 217-222. https://doi.org/10.1071/HC12217

Nilsen, P. (2010). Brief alcohol intervention - where to from here? Challenges remain for research and practice. Addiction, 105(6), 954-959. https://doi.org/10.1111/j.1360-0443.2009.02779.x

Nygaard, P., \& Aasland, O. G. (2011). Barriers to implementing screening and brief interventions in general practice: Findings from a qualitative study in Norway. Alcohol and Alcoholism, 46 (1), 52-60. https://doi.org/10.1093/alcalc/agq073

Nygaard, P., Paschall, M. J., Aasland, O. G., \& Lund, K. E. (2010). Use and barriers to use of screening and brief interventions for alcohol problems among Norwegian general practitioners. Alcohol and Alcoholism, 45(2), 207-212. https://doi.org/ 10.1093/alcalc/agq002

Peabody, J. W., Luck, J., Glassman, P., Dresselhaus, T. R., \& Lee, M. (2000). Comparison of vignettes, standardized patients, and chart abstraction: A prospective validation study of 3 methods for measuring quality. Journal of the American Medical Association, 283(13), 1715-1722. https://doi.org/10.1001/jama.283.13.1715

Peabody, J. W., Luck, J., Glassman, P., Jain, S., Hansen, J., Spell, M., \& Lee, M. (2004). Measuring the quality of physician practice by using clinical vignettes: A prospective validation study. Annals of Internal Medicine, 141(10), 771-780. https:// doi.org/10.7326/0003-4819-141-10-200411160-00008

Prentice-Dunn, S., McMath, B. F., \& Cramer, R. J. (2009). Protection motivation theory and stages of change in sun protective behaviour. Journal of Health Psychology, 14(2), 297-305. https://doi.org/10.1177/1359105308100214

Rapley, T., May, C., \& Kaner, E. F. (2006). Still a difficult business? Negotiating alcohol-related problems in general practice consultations. Social Science and Medicine, 63(9), 2418-2428. https://doi.org/10.1016/j.socscimed.2006.05.025

Schwarzer, R., Lippke, S., \& Luszczynska, A. (2011). Mechanisms of health behavior change in persons with chronic illness or disability: The Health Action Process Approach (HAPA). Rehabilitation Psychology, 56(3), 161-170. https://doi.org/10.1037/ a0024509

Schröder, C., Behnke, M., Gastmeier, P., Schwab, F., \& Geffers, C. (2015). Case vignettes to evaluate the accuracy of identifying healthcare-associated infections by surveillance persons. Journal of Hospital Infection, 90(4), 322-326. https://doi.org/ 10.1016/j.jhin.2015.01.014

Sowden, G. L., Vestal, H. S., Stoklosa, J. B., Valcourt, S. C., Peabody, J. W., Keary, C. J., Nejad, S. H., Caminis, A., \& Huffman, J. C. (2017). Clinical case vignettes: A promising tool to assess competence in the management of agitation. Academic Psychiatry, 41, 364-368. https://doi.org/10.1007/s40596-016-0604-1

Town, R., Kane, R., Johnson, P., \& Butler, M. (2005). Economic incentives and physicians' delivery of preventive care: A systematic review. American Journal of Preventive Medicine, 28(2), 234-240. https://doi.org/10.1016/j.amepre.2004.10.013

World Health Organization. (2004). ICD-10: International statistical classification of diseases and related health problems (10th revision, 2nd ed.). WHO.

World Health Organization. (2017). WHO alcohol brief intervention training manual for primary care. World Health Organization Regional Office for Europe.

World Health Organization. (2018). Global status report on alcohol and health 2018. WHO.

White, A. M., Tapert, S., \& Shukla, S. D. (2018). Binge drinking: Predictors, patterns, and consequences. Alcohol Research, 39(1), 1-3. PMCID: PMC6104965.

Wigfield, A., \& Eccles, J. S. (2000). Expectancy-value theory of achievement motivation. Contemporary Educational Psychology, 25(1), 68-81. https://doi.org/10.1006/ceps.1999.1015

Wilson, G. B., Lock, C. A., Heather, N., Cassidy, P., Christie, M. M., \& Kaner, E. F. (2011). Intervention against excessive alcohol consumption in primary health care: A survey of GPs' attitudes and practices in England 10 years on. Alcohol and Alcoholism, 46(5), 570-577. https://doi.org/10.1093/alcalc/agr067

\section{History}

Received September 16, 2020

Revision received January 19, 2021

Accepted February 12, 2021

Published online May 3, 2021

\section{Conflict of Interest}

The authors declared no potential conflicts of interest with respect to the research, authorship, and/or publication of this article.

\section{Publication Ethics}

Voluntary participation was implemented by the Ethics Committee of the University of Halle.

\section{Funding}

This work has been supported by the Bundesministerium für Gesundheit (grant no. ZMVI5-2514DSM209) to Thomas Fankhänel.

\section{ORCID}

Thomas Fankhänel

(iD) https://orcid.org/0000-0002-2500-5372

\section{Thomas Fankhänel}

Martin-Luther-University Halle-Wittenberg

Magdeburgerstraße 8

06112 Halle

Germany

thomas.fankhaenel@srh.de 


\section{Appendix}

\section{Example Vignettes}

Example Vignette 1 (harmful alcohol consumption, high adherence, above standard financial reimbursement).

Please bring to mind the following situation:

A patient consults you in your general practice. Repeatedly he complains about stomach-ache. According to his liver values, an alcohol problem may be suspected. You raise the suspicion of harmful alcohol consumption and suggest to him a reduction of his alcohol consumption.

The patient agrees with you, even acknowledging that an alcohol problem may exist and a lifestyle change should be considered. For your brief intervention, you would receive a financial compensation of $36 €$.

Example Vignette 2 (binge drinking, low adherence, standard financial reimbursement).

Please bring to mind the following situation:

A patient consults you in your general practice. He asks you for sick leave because of being stressed. During your anamnesis, you receive the information that he would be drunk several times at parties. You raise the suspicion of binge drinking and suggest to him a reduction of his alcohol consumption. The patient replies however that he does not have an alcohol problem and he would not accept a lifestyle change. For your brief intervention, you would receive a financial compensation of $18 €$. 